\title{
Total quality index of commercial oyster mushroom Pleurotus sapidus in modified atmosphere packaging
}

\author{
Wan Abd Al Qadr Imad Wan-Mohtar \\ Functional Omics and Bioprocess Development Laboratory, \\ Institute of Biological Sciences, University of Malaya, Kuala Lumpur, Malaysia \\ Anita Klaus \\ Institute for Food Technology and Biochemistry, \\ University of Belgrade, Belgrade, Serbia \\ Acga Cheng \\ Functional Omics and Bioprocess Development Laboratory, \\ Institute of Biological Sciences, University of Malaya, Kuala Lumpur, \\ Malaysia, and \\ Shardana Aiga Salis and Sarina Abdul Halim-Lim \\ Food Science and Technology, University Putra Malaysia, Serdang, Malaysia
}

\begin{abstract}
Purpose - The purpose of this paper is to identify the strain of oyster mushroom (OM) Pleurotus sapidus cultivated in a local (commercial) farm, and to generate a total quality index (TQI) on the strain using different modified atmosphere packaging (MAP) gas mixtures.

Design/methodology/approach - A phylogenetic tree was constructed using the MEGA software to identify the specific strain of P. sapidus grown in a local farm. The effects of MAP on fresh fruiting bodies of the identified strain were determined under three conditions: high carbon dioxide packaging (HCP: 20 per cent $\mathrm{CO}_{2}, 15$ per cent $\mathrm{O}_{2}$ ), low carbon dioxide packaging $\left(\mathrm{LCP}: 2\right.$ per cent $\mathrm{CO}_{2}, 30$ per cent $\mathrm{O}_{2}$ ) and high nitrogen packaging (HNP: 85 per cent $\mathrm{N}_{2}, 15$ per cent $\mathrm{O}_{2}$ ). All samples were stored at $4{ }^{\circ} \mathrm{C}$ for up to ten days, and subjected to total phenolic content (TPC), colour retention (CR) and sensory analysis. Quality parameters such as chewiness and odour were used to obtain the TQI.

Findings - From the phylogenetic analysis, a new strain (P. sapidus strain QDR) with 99 per cent similarity to $P$. sapidus was identified. Among the three MAP treatments, HCP recorded the highest TPC (2.85 mg GAE/g) and CR (60.36) after ten days, although only its CR was significantly different $(p<0.05)$ from the control. Feedback from 30 sensory panellists indicated that both HCP and LCP were generally more effective in retaining the colour-odour of OM. The optimum TQI for HCP was obtained based on the observed parameters, which is useful for the large-scale packaging of OM.

Originality/value - Scientific evidence has revealed that packaging trend for commercially grown OM affects consumer's acceptance.

Keywords Modified atmosphere packaging, Oyster mushroom, Phylogenetic analysis, Pleurotus sapidus, Total quality index

Paper type Research paper

\section{Introduction}

In the past ten years, the consumption and production of commercial oyster mushrooms (OMs) have been increasing globally (Jafri et al., 2013). The Pleurotus species are known for having a unique flavour, a good texture profile and for being nutritious (Wan-Mohtar et al., 2018), which increases consumer demand for the product (Sapata et al., 2009). Mushrooms comprise 32.7 per cent crude protein, 2.4 per cent crude fat and 47.7 per cent carbohydrate, thus representing a healthy dietary option (Akbarirad et al., 2013).
\end{abstract}

OM Pleurotus sapidus

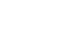


$\mathrm{BFJ}$

121,8

1872

Researchers have reported changes occurring after the harvesting process, such as browning, loss of moisture, altered flavour profile, shorter shelf-life and decreased quality of mushroom produced, thus affecting marketability (Brennan et al., 2000; Vukosavljević et al., 2009). As a result, increased understanding of the packaging process, properties, storage and distribution of mushrooms is required, as these factors impact the shelf-life and quality of mushrooms (Akbarirad et al., 2013).

Mushrooms are generally placed in a plastic punnet and wrapped with PVC film. However, due to the poor vapour permeability of this barrier and the high transpiration rate of mushrooms, this format can lead to undesirable condensation inside the package (Gao et al., 2014). A study on modified atmosphere packaging (MAP) found that controlling the microbial growth and chemical degradation contributes to greater probability of maintaining the quality of mushrooms, thereby extending their shelf-life (Djekic et al., 2017). There are four core parameters to consider when designing MAP: product characteristics, packaging material permeability, gas concentration (carbon dioxide: $\mathrm{CO}_{2}$ and oxygen: $\mathrm{O}_{2}$ ) and temperature dependence. Passive MAP is achieved when fresh produce reacts naturally with the packaging's modified surrounding atmosphere, by producing $\mathrm{CO}_{2}$ and consuming $\mathrm{O}_{2}$ (Fonseca et al., 2002), while active MAP comprises controlling and mixing specific gases inside the chosen packaging material (Robertson, 2006). However, inappropriate MAP designs such as improper gas levels lead to high respiration rates and decrease mushroom shelf-life according to Fonseca et al. (2002). The quality of MAP for mushrooms relates to texture, microbial count, whiteness, colour changes and sensory characteristics, which are crucial in analysing the deterioration rate (Mohapatra et al., 2011; Argyropoulos et al., 2011), thus affecting consumer acceptance.

Mushroom quality and consumer demands have been the main priority in improving the inner packaging atmosphere. To avoid unwanted odours and browning behaviour from in retail mushrooms, appropriate MAP designs are necessary (Djekic et al., 2017). Thus, this research aimed to study three different active MAP mushroom packaging formats, using nine core parameters (total phenolic content (TPC), $L^{*}, a^{*}, b^{*}$, hardness, cohesiveness, chewiness, odour and sensory analysis), for ensuring that the quality of fruiting bodies is maintained. These parameters were established as the preferred post-MAP mushroom according to 30 panellists. The total quality index (TQI) was generated by measuring the obtained standard quality index. The use of TQI in summarizing the important parameters for Malaysian commercial mushroom quality has not previously been reported. This strategy offers significant potential for industrial applications (Ares et al., 2007), particularly with respect to Southeast Asian mushrooms production.

\section{Materials and methods}

\subsection{Source of OM and fruiting body preparation}

Commercial OMs were obtained from an established farmhouse at the University Agriculture Park (Mushroom Unit), Universiti Putra Malaysia. High-quality fresh mushrooms were selected based on uniformity of size (cap diameter $\sim 5 \mathrm{~cm}$ ) and colour. Any extraneous materials were removed, and the fruiting bodies were thoroughly cleaned. The mushrooms were then transferred to the laboratory using refrigerated containers $\left(8-10{ }^{\circ} \mathrm{C}\right)$ and stored at $4{ }^{\circ} \mathrm{C}$, the desired temperature for the respiration rate reduction. Selected mushrooms were individually weighed and packed in $30 \mu \mathrm{m}$-thick polypropylene (PP) bags $(120 \mathrm{~mm} \times 80 \mathrm{~mm})$ (permeability as suggested by Exama et al., 1993).

\subsection{P. sapidus strain QDR isolation and phylogenetic tree analysis}

The stipe of the fruiting body of P. sapidus strain QDR samples was isolated and transferred to potato dextrose agar (PDA, Sigma-Aldrich, Dorset, UK) plates. After ten days of incubation, the uncontaminated mycelium on the plate was cut $\left(5 \mathrm{~mm}^{3}\right)$ and transferred into 
sterile $1.5 \mathrm{~mL}$ Eppendorf tubes for fungal DNA extraction based on the technique of Liu et al. (2000). A small piece of mycelia was placed using a sterile toothpick into $1.5 \mathrm{~mL}$ Eppendorf tubes containing $500 \mu \mathrm{L}$ of lysis buffer ( $400 \mathrm{mM}$ Tris- $\mathrm{HCl}$ (pH 8.0), $60 \mathrm{mM}$ EDTA (pH 8.0), 1 per cent sodium dodecyl sulphate, $150 \mathrm{mM} \mathrm{NaCl}$ ) for mycelial disruption. The tubes were placed at room temperature for $10 \mathrm{~min}$. Next, $150 \mu \mathrm{L}$ of potassium acetate $(\mathrm{pH}$ $4.8 ; 60 \mathrm{~mL}$ of $5 \mathrm{M}$ potassium acetate, $11.5 \mathrm{~mL}$ of glacial acetic acid, and $28.5 \mathrm{~mL}$ of distilled water) was added into each tube, and the contents were vortexed. After $11,000 \times \mathrm{g}$ centrifugation at $1 \mathrm{~min}$, the supernatant was transferred to a fresh $1.5 \mathrm{~mL}$ Eppendorf tube, and an equal volume of isopropyl alcohol was added and mixed. Tubes were spun at $10,000 \times \mathrm{g}$ for $2 \mathrm{~min}$, and the supernatant was discarded. The resultant DNA pellet was washed with 70 per cent ethanol $(300 \mu \mathrm{L})$.

Next, the pellet was centrifuged at $10,000 \times \mathrm{g}$ for $1 \mathrm{~min}$ and the resultant supernatant was discarded. The DNA pellet was air dried and dissolved in $50 \mu \mathrm{L}$ of $1 \mathrm{X}$ Tris-EDTA to generate purified fungal gDNA. Fungal identification was performed using two internal transcribed spacer (ITS) primers, ITS1 (5'- TCCGTAGGTGAACCTGCGG-3') and ITS4 (5'TCCTCCGCTTATTTGATATGC-3'). Polymerase chain reaction (PCR) amplification was carried out in $25 \mu \mathrm{L}$ reaction mixtures, following the protocols of Tamura et al. (2013) and Liu et al. (2000). Each PCR reaction contained $0.5 \mu \mathrm{M}$ of each primer, $1.5 \mu \mathrm{M} \mathrm{MgCl} 2,0.2 \mu \mathrm{M}$ of dNTP mix, 0.5 U DNA polymerase, PCR buffer (Promega, Madison, WI, USA) and ultrapure water. The targeted fragments were amplified using an Eppendorf Mastercycler gradient (Eppendorf, Hamburg, Germany) according to the following protocol: $95{ }^{\circ} \mathrm{C}$ for 2 min; followed by 25 cycles of $95^{\circ} \mathrm{C}$ for $15 \mathrm{~s}, 60^{\circ} \mathrm{C}$ for $30 \mathrm{~s}$ and $72^{\circ} \mathrm{C}$ for $30 \mathrm{~s}$; and 10 min at 72 ${ }^{\circ} \mathrm{C}$ for the final extension. PCR products were separated on standard 1 per cent Agarose gels at $80 \mathrm{~V}$ for $1 \mathrm{~h}$, purified using a PCR Purification Kit (Tiangen Biotech Co., Beijing, China) and sequenced bidirectionally using a BigDye ${ }^{\circledR}$ Terminator v3.1 Cycle Sequencing Kit (Applied Biosystems Co., MA, USA). The different sequences of the same or different species were entered into BLAST and the ten closest matches obtained from the database.

A phylogenetic tree was generated by calculating the evolutionary distance $\left(K_{\text {nuc }}\right)$ between sequences of identical fungal species using the neighbour-joining (NJ) method as described by Ab Kadir et al. (2016) with Molecular Evolutionary Genetic Analysis software version 6.0 (Tamura et al., 2013). The isolated commercial fungus was identified as the same species by the closest $K_{\text {nuc }}$.

\subsection{Modified atmosphere packaging (MAP)}

Selected OMs were carefully packed under three active MAP treatments: high carbon dioxide packaging ( $\mathrm{HCP}: 20$ per cent $\mathrm{CO}_{2}+15 \mathrm{O}_{2}$ ), low carbon dioxide packaging (LCP: 30 per cent $\mathrm{O}_{2}$ +2 per cent $\left.\mathrm{CO}_{2}\right)$ and high nitrogen packaging $\left(\mathrm{HNP}: 85\right.$ per cent $\mathrm{N}_{2}, 15$ per cent $\mathrm{O}_{2}$ ) using an MAP unit (Plate 1). As a better control, a passive modified atmosphere with initial air inside was denoted as the normal atmosphere treatment. MAP was utilised with three packages for chemical properties and three packages for textural and sensory properties. The packages were stored under constant conditions of temperature and relative humidity of $4{ }^{\circ} \mathrm{C}$ and 95 per cent, respectively, for up to 10 days, with testing on day 5 and day 10 .

\subsection{Chemical analysis}

Polysaccharide extraction was performed according to Klaus and Nikšić (2007) and Wan-Mohtar, Malek, Harvey and McNeil (2016), Wan-Mohtar, Latif, Harvey and McNeil (2016) and Wan-Mohtar, Ab Kadir and Saari (2016). MAP-treated mushrooms (MTM) (15 g) were blended using a blender (Waring Lab, Madison, WI, USA). MTM was washed with 96 per cent of ethanol (v/v) for $24 \mathrm{~h}$ at room temperature and consequently dried in a food dehydrator for $1 \mathrm{~h}$ at $40{ }^{\circ} \mathrm{C}$. The dried MTM was extracted in $2 \mathrm{~L}$ of distilled water and subjected hot water extraction ( $45 \mathrm{~min}, 121^{\circ} \mathrm{C}$ in an autoclave). After cooling, the 
$\mathrm{BFJ}$ 121,8

\section{4}

Plate 1.

Oyster mushroom MAP preparation from a commercial farm

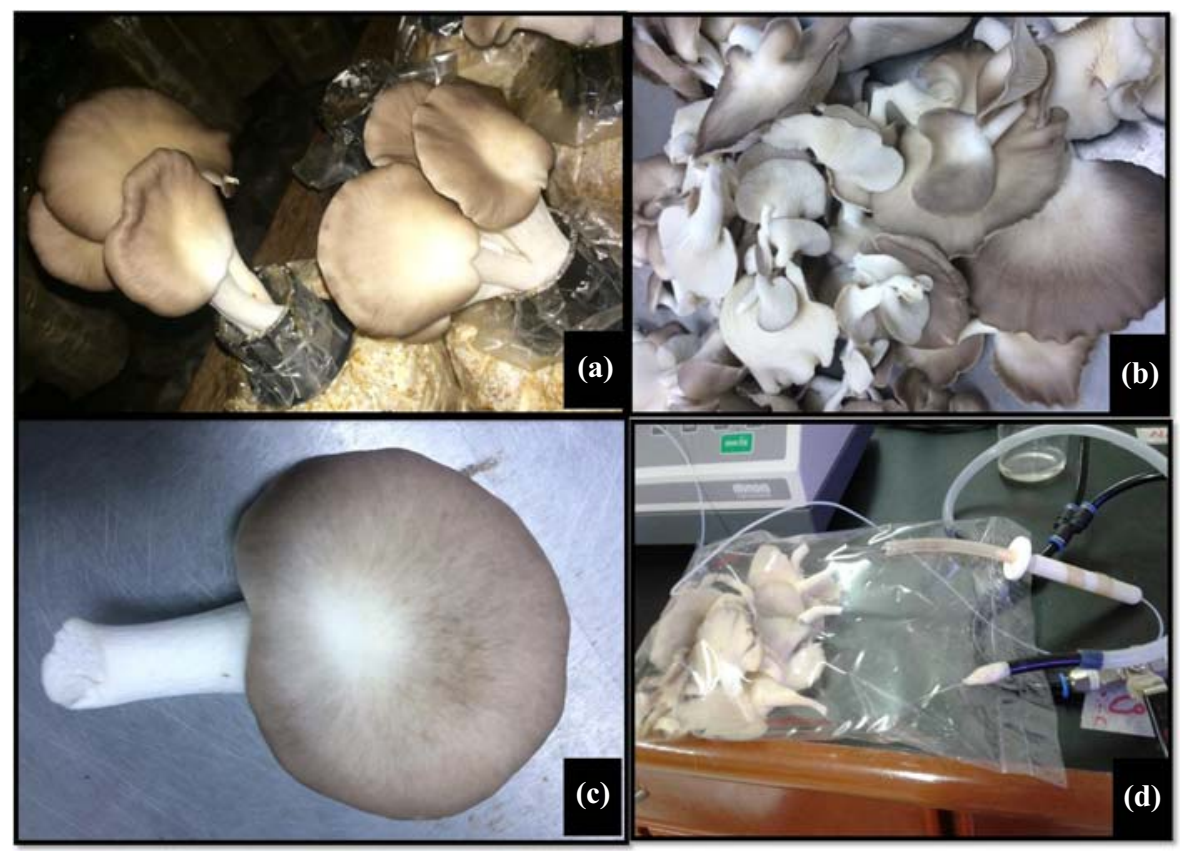

Notes: (a) The first harvest at 8 a.m.; (b) the selection of quality fruiting bodies; (c) oyster mushroom packaging; (d) modified atmosphere gas needle procedure

sample was centrifuged for $15 \mathrm{~min}$ at $8,000 \mathrm{rpm}$. Using a freeze dryer, the concentrated supernatant was mixed with 1:3 cold ethanol 99.8 per cent and stored overnight at $4{ }^{\circ} \mathrm{C}$. The precipitated polysaccharide from MTM was centrifuged for $15 \mathrm{~min}$ at $6,000 \mathrm{rpm}$. TPC of freeze-dried MTM extract was determined.

\subsection{Total phenolic content}

The TPC of MAP-treated mushrooms was determined using the Folin-Ciocalteu method (Bi et al., 2016). Briefly, $40 \mu \mathrm{L}$ of sample was mixed with $1.8 \mathrm{~mL}$ Folin-Ciocalteu reagent (Kemika, Zagreb, Croatia) (1:9 dilution with water) followed by $1.2 \mathrm{~mL}$ of 7.5 per cent sodium carbonate after $5 \mathrm{~min}$. The mixture was thoroughly mixed and incubated for $1 \mathrm{~h}$ in a dark room. Spectrophotometric absorbance was measured at $630 \mathrm{~nm}$. The Gallic acid standard (Fluka Chemica, Switzerland) used for calibration was at a concentration of 20-100 ppm. The phenolic content of each sample was expressed as $\mathrm{mg}$ of Gallic acid equivalent per gram (mg GAE/g) of mushrooms.

\subsection{Colour characteristics}

MAP-treated mushrooms were analysed using a CR-410 Chroma Meter $-\Delta E^{*}$ ab 0.07 standard deviation (Konica Minolta Sensing Americas, Williams Drive Ramsey, NJ, USA) Integrated with SpectraMagic NX software at room temperature. Colour changes of mushroom samples were standardized by Hunter colour parameters $L^{*}, a^{*}$ and $b^{*}$. The colorimeter was calibrated using black-and-white tiles for each sample set analysis. Three noticeable parameters from the same mushroom pileus surface were determined and the $L^{*}, a^{*}$ and $b^{*}$ values were recorded. An $L$ of 100 was equivalent to pure white, while an $L$ of 0 was matt black. 


\subsection{Texture profiles}

The textural profile of each sample was analysed using a texture analyser whereby mushroom caps were compressed to 20 per cent of their original height using a compression plate probe at a speed of $21 / \mathrm{mms}$ (Djekic et al., 2017). The hardness and chewiness of each sample were calculated from the curve of force vs time recorded data. Texture profile analysis (TPA) or a "two-bite test" was carried out on three mushroom caps at room temperature $\left(25^{\circ} \mathrm{C}\right)$ for each treatment.

\subsection{Sensory evaluation}

To determine the acceptance of potential consumers, 30 panellists were asked to evaluate each treated mushroom sample by answering a questionnaire. This questionnaire used a hedonic scale and focussed on the colour and odour attributes of the mushrooms. The fivepoint hedonic scale for colour was as follows: 5 was too dark, 4 was slightly dark, 3 was the same as control, 2 was slightly light and 1 was too light. For the odour attribute, 5 was too strong, 4 was slightly strong, 3 was the same as control, 2 was slightly weak and 1 was too weak. Each of the samples was labelled with a random three-digit code from The Table of Random Digits and provided in plain containers that were closed and odourless.

\subsection{Total quality index}

As a cost-effective measurement, TQI was determined based on the observed parameters. Two groups of quality parameters were established according to Finotti et al. (2007) and Djekic et al. (2017): "measured value of fresh mushroom quality parameter" (first group with a target value). The rule indicated that quality is better when the value is nearer to the target value of the parameter. Hence, QI was calculated as:

$$
\mathrm{QI}=\left|2\left(x_{i}-T\right) /\left(x_{\max }-x_{\min }\right)\right|,
$$

where QI is the quality index for a parameter for the following: $x_{i}=$ measured value in the subset of values; $T=$ target value; $X_{\max }=$ maximal value; $X_{\min }=$ minimal value in the subset of values.

The quality parameters included in first group were (with a target value): Chewiness $=$ 751.20, hardness $=10.71$, cohesiveness $=0.86$, odour $=1$ and $\mathrm{TPC}=2.93$.

For the second group, "quality is better if the value is smaller" was applied, and the QI for this group was calculated as:

$$
\mathrm{QI}=x_{i} / x_{\max },
$$

where, $\mathrm{QI}=$ quality index for a specific quality parameter; $X_{i}=$ measured value in the subset of values; $X_{\max }=$ maximal value in the subset of values.

The quality parameters included in second group were $L^{*}, a^{*}, b^{*}$ and colour attributes for sensory.

The overall quality index (TQI) was calculated as:

$$
\mathrm{TQI}=\left[\sum_{j=1}^{N}\left(Q I_{j}\right)^{2}\right]^{1 / 2} .
$$

The rule applied was that the TQI was worse if the vector was farther from the origin and the TQI was better if the vector was nearer to the origin. 
BFJ
121,8

\section{6}

2.10 Statistical analysis

For statistical analysis, Minitab 18 software was used to run the analysis of variance (ANOVA) (Minitab Inc., USA), and triplicate values were expressed as mean \pm standard deviation unless stated otherwise. This was used to determine the significant differences among testing means at a $p$-value of 1 at $\alpha=0.05$.

\section{Results and discussion}

3.1 Molecular characteristics of commercial OM for growers

Fresh OM was selected for MAP treatments. An amplified product of approximately $670 \mathrm{bp}$ in size was obtained as shown in Figure 1. The product was sequenced and aligned with the top-10 related species based on NCBI BLAST. OM was found to be 99 per cent similar to P. pulmonarius, P. sajor-caju, Lentinus sajor-caju and P. sapidus. Based on the phylogenetic tree (Figure 2$)$, the evolutionary distance $\left(K_{n u c}\right)$ values at clade A showed that the isolate was closely related to P. sapidus strain xiaxiu $99018 \mathrm{~S}$ compared with $L$. sajor-caju strain S2005 18S.

The concluded local $P$. sapidus strain may solve the society-practice-related issue in misidentifying the correct available OM species (P. sajor-caju, P. ostreatus and P. pulmonarius) in the market. The conventional commercial mushroom farm is facing logistic problems such as storage, incorrect mushroom species declaration and packaging for vendor distribution. Such problems can be solved by intellectual property protection and influencing public attitudes to avoid vendor exploitation primarily due to customers lack ability in differentiating commercial OM species. As one of the highest-valued crops, the land area for OM cultivation will increase from 78 ha in 2010 to 340 ha in 2020 (Hamid et al., 2013), which warranted the importance of individual OM molecular recognition for protecting local mushroom growers.

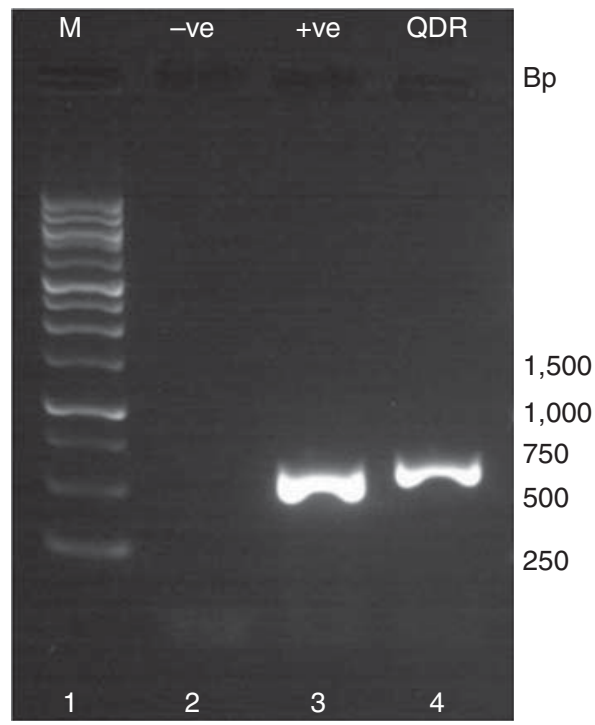

Notes: The gel consists of 1 per cent agarose and was run with 1 per cent TE buffer at $80 \mathrm{~V}$. Lanes 1 and 5: DNA marker; Lane 2: PCR no template control; Lane 3: positive control fungal gDNA; Lane 4: PCR QDR product
Figure 1.

Ethidium bromide fluorescence image showing electrophoresis of Pleurotus sapidus strain QDR PCR product 


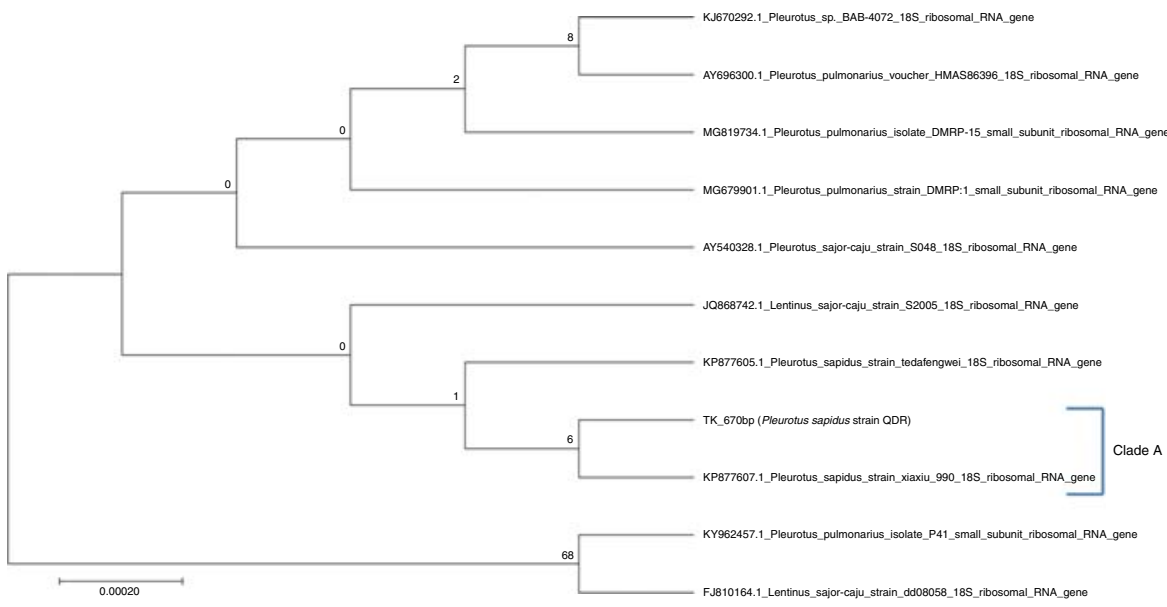

Notes: Branch 1: Pleurotus sapidus strain tedafengwei 18 S=KP877605; Pleurotus sapidus strain xiaxiu_990 18S=KP877607.1. Bar 0.00020 Knис
OM Pleurotus

sapidus

1877

Figure 2.

Neighbour-joining

phylogenetic tree showing the

relationships of

Pleurotus sp. isolate

TK_670bp (strain

QDR) and top-10

BLAST species based on $18 \mathrm{~S}$ rRNA gene sequences

\subsection{Total phenolic content}

Under abiotic stress condition such as MAP, the TPC absorbs and neutralises free radical compounds (Jafri et al., 2013). Because storage conditions can influence variations in TPC, different MAP treatments for OMs were analysed over storage time. As shown in Table I, TPC in grey OMs increased from day 5 to day 10 except for HNP-treated samples, as reported by Jafri et al. (2013), indicating that the TPC of OMs increases with storage time regardless of additives used. This finding supports that of Djekic et al. (2017), who showed an incremental increase in TPC in button mushrooms after a sudden decrease among MAP-treated samples in the first 10 days.

TPC increased significantly $(p<0.05)$ in LCP and control OMs when the packaging was high in oxygen (Table I). Such value increment is due to stress conditions that can cause phenolic compounds to be generated and to oxidise readily in the presence of oxygen. Furthermore, HNP showed a significant reduction $(p<0.05)$ in TPC value, which may be attributable to the breakdown of phenolic compounds by enzymatic activity (Selcuk and Erkan, 2015). Mushrooms in HNP have been shown to be involved in enzymatic oxidation and browning processes as they undergo colour changes and a reduction in TPC concentration, which is affected by the availability of nitrogen (Cayupan et al., 2011). Nonetheless, in the present study, HCP retained the highest TPC after 5 days and showed only a mild reduction in the second half of the study, compared with other MAP treatments.

\begin{tabular}{lcr}
\hline & \multicolumn{2}{c}{ Total phenolic content (mg GAE/g) } \\
Atmosphere packaging & Day 5 & Day 10 \\
\hline Control & $2.69 \pm 0.13^{\mathrm{aB}}$ & $3.25 \pm 0.08^{\mathrm{aA}}$ \\
HNP & $2.22 \pm 0.07^{\mathrm{bA}}$ & $1.97 \pm 0.01^{\mathrm{bB}}$ \\
LCP & $2.72 \pm 0.00^{\mathrm{aB}}$ & $2.99 \pm 0.06^{\mathrm{aA}}$ \\
HCP & $2.86 \pm 0.05^{\mathrm{aA}}$ & $3.03 \pm 0.19^{\mathrm{aA}}$
\end{tabular}

Notes: Values are mean \pm standard error (duplicate). Mean values with different lower case within each column are significantly different $(p<0.05)$. Mean values with different capital case within the same row are significantly different $(p<0.05)$. Control is normal air packaging. HNP is high nitrogen packaging. LCP is low carbon dioxide packaging. HCP is high carbon dioxide packaging

Table I.

Total phenolic content of oyster mushroom over storage time in MAP 


\section{$\mathrm{BFJ}$ 121,8}

1878

\subsection{Colour characteristics}

Colour is crucial in determining the quality of mushrooms as it is related to consumer acceptance and commercial value (Singh et al., 2010). Therefore, the colour quality of grey OMs on active MAP was evaluated using a colorimeter. From day 5 to day 10, the mushroom colour gradually changed from white to brown, caused by the TPC in mushroom (enzymatic browning) which decreased the $L^{*}$ value (loss of brightness and become darker) and increases the $a^{*}$ and $b^{*}$ values (redness and yellowness increment) (Liu et al., 2013). As shown in Table II, the $L^{*}$ values of mushrooms on day 5 were 62.11 (HNP), 65.77 (LCP), 67.71 (control) and 69.94 (HCP). According to Baars et al. (2000), the $L^{*}$ value of mushroom is low, at approximately 70 , after 5 days of storage. On day 10 , the $L^{*}$ value of mushrooms decreased for each MAP treatment, indicating a reduction in brightness. There was a significant change in $L^{*}$ value $(p<0.05)$ for all MAP treatments over storage time but no change $(p>0.05)$ on the same storage day, except for control and HNP at day 10. Mushrooms packed in HNP (52.28) had the lowest $L^{*}$ values, indicating the highest colour changes over storage time by dark zone formation and a low-quality appearance. Furthermore, the $L^{*}$ value of HCP (60.36) was the highest, indicating the lightest colour with the highest-quality appearance (freshest).

The value of $a^{*}$ at day 5 was within the range of 1.05-1.50 for active MAP. Baars $e t a l$. (2000) also reported that mushrooms have a low $a^{*}$ value, in the range of $0-1$, indicating the absence of redness compared with natural white. However, at day 10 , the $a^{*}$ value increased for active MAP, with the most significant change $(p<0.05)$ shown for HCP over storage time, but no change $(p<0.05)$ for control, HNP and LCP. Under active MAP storage conditions, there was a significant different $(p<0.05)$ with respect to highest and lowest $a^{*}$ value for HCP at day 10 . The $b^{*}$ value showed a significant difference $(p<0.05)$ across different MAP treatments. At day 5 , the $b^{*}$ value of mushrooms was in the range of 11.80-12.90. Baars et al. (2000) previously reported that $b^{*}$ value within the range of $6-10$ were indicative of slight yellowness in appearance. Our data showed that HCP was the most effective packaging strategy for efficiently retarding browning effects compared with HNP, LCP and control.

\subsection{Texture profiles}

To determine the texture of MAP-treated mushrooms, TPA or a "two-bite test" was performed (Ares et al., 2006). As shown in Table III, mushroom hardness decreased from day 5 to day 10 for all MAP treatments, with the highest value observed for $\mathrm{HNP}(p<0.05)$ compared with HCP, LCP and control, which is in agreement with the findings of Djekic et al. (2017).

\begin{tabular}{|c|c|c|c|c|c|c|}
\hline \multirow[b]{2}{*}{$\begin{array}{l}\text { Atmosphere } \\
\text { packaging }\end{array}$} & \multicolumn{2}{|c|}{$L^{*}$} & \multicolumn{2}{|c|}{$a^{*}$} & \multicolumn{2}{|c|}{$b^{*}$} \\
\hline & Day 5 & Day 10 & Day 5 & Day 10 & Day 5 & Day 10 \\
\hline Control & $67.71 \pm 0.00^{\mathrm{aA}}$ & $54.92 \pm 0.57^{\mathrm{bB}}$ & $1.49 \pm 0.11^{\mathrm{aA}}$ & $1.64 \pm 0.02^{\mathrm{bA}}$ & $12.89 \pm 0.10^{\mathrm{aB}}$ & $20.10 \pm 0.11^{\mathrm{bcA}}$ \\
\hline $\mathrm{HNP}$ & $62.11 \pm 0.75^{\mathrm{aA}}$ & $52.28 \pm 0.49^{\mathrm{cB}}$ & $1.48 \pm 0.65^{\mathrm{aA}}$ & $1.79 \pm 0.04^{\mathrm{aA}}$ & $13.64 \pm 1.25^{\mathrm{aB}}$ & $23.90 \pm 0.92^{\mathrm{aA}}$ \\
\hline LCP & $65.77 \pm 4.31^{\mathrm{aA}}$ & $58.7 \pm 0.86^{\mathrm{aA}}$ & $1.18 \pm 0.18^{\mathrm{aA}}$ & $1.61 \pm 0.04^{\mathrm{bA}}$ & $13.57 \pm 0.23^{\mathrm{aB}}$ & $21.25 \pm 0.59^{\mathrm{bA}}$ \\
\hline \multirow[t]{2}{*}{ HCP } & $69.94 \pm 0.18^{\mathrm{aA}}$ & $60.36 \pm 0.33^{\mathrm{aB}}$ & $1.07 \pm 0.01^{\mathrm{aB}}$ & $1.53 \pm 0.03^{\mathrm{bA}}$ & $11.81 \pm 0.04^{\mathrm{aB}}$ & $18.94 \pm 0.18^{\mathrm{cA}}$ \\
\hline & \multicolumn{2}{|c|}{ Hardness } & \multicolumn{2}{|c|}{ Cohesiveness } & \multicolumn{2}{|c|}{ Chewiness } \\
\hline $\begin{array}{l}\text { Atmosphere } \\
\text { packaging }\end{array}$ & Day 5 & Day 10 & Day 5 & Day 10 & Day 5 & Day 10 \\
\hline Control & $9.78 \pm 0.13^{\mathrm{aA}}$ & $6.08 \pm 0.00^{\mathrm{bB}}$ & $0.87 \pm 0.01^{\mathrm{aA}}$ & $1.05 \pm 0.18^{\mathrm{aA}}$ & $727.47 \pm 4.81^{\mathrm{aA}}$ & $620.72 \pm 13.63^{\mathrm{bB}}$ \\
\hline HNP & $10.06 \pm 0.62^{\mathrm{aA}}$ & $6.58 \pm 0.58^{\mathrm{bB}}$ & $0.86 \pm 0.01^{\mathrm{aA}}$ & $0.90 \pm 0.05^{\mathrm{aA}}$ & $678.92 \pm 5.06^{\mathrm{bA}}$ & $465.31 \pm 20.97^{\mathrm{cB}}$ \\
\hline LCP & $10.20 \pm 0.94^{\mathrm{aA}}$ & $8.88 \pm 0.37^{\mathrm{aA}}$ & $0.85 \pm 0.03^{\mathrm{aA}}$ & $0.89 \pm 0.02^{\mathrm{aA}}$ & $729.70 \pm 9.67^{\mathrm{aA}}$ & $686.90 \pm 5.44^{\mathrm{aB}}$ \\
\hline $\mathrm{HCP}$ & $10.59 \pm 0.28^{\mathrm{aA}}$ & $9.12 \pm 0.65^{\mathrm{aA}}$ & $0.85 \pm 0.02^{\mathrm{aA}}$ & $0.86 \pm 0.06^{\mathrm{aA}}$ & $742.09 \pm 2.40^{\mathrm{aA}}$ & $702.84 \pm 3.06^{\mathrm{aA}}$ \\
\hline
\end{tabular}

Table II.

Colour parameter and textural profile for each MAP over storage time 
According to Pardo et al. (2010), membrane changes determine loss of firmness or softening of mushrooms during post-harvest storage. Textural changes are associated with hyphae shrinkage, polysaccharide and protein degradation, central vacuole disruption and intercellular space expansion at the pilei surface (Zivanovic et al., 2000). These findings suggest that HNP is the least effective method for retaining mushroom firmness.

For mushroom cohesiveness, there was no significant difference $(p<0.05)$ between MAP-treated mushrooms under both different and the same storage durations. However, there was a slight increase in cohesiveness among all MAP-treated mushrooms from day 5 to day 10 , with HNP showing the highest value by the end of storage. The cohesiveness of mushrooms increases with storage time, caused by the absorption of moisture into the capillary voids (Kotwaliwale et al., 2007) and an increase in hyphal wall rigidity (Ares et al., 2006; Zivanovic et al., 2000). These processes occur due to increased chitin content and the formation of covalent bonds with R-glucan (Zivanovic et al., 2000).

Mushroom chewiness was also affected by MAP treatments, with values decreasing from day 5 to day 10. There was a significant difference $(p<0.05)$ for HNP at the same storage conditions as other treatments at both day 5 and day 10 . However, HCP was not significantly different $(p>0.05)$ over storage time compared with HNP, LCP and control. According to Marangoni et al. (1996), decreased chewiness over storage time is related to the loss of turgor and barrier functions, thus causing changes in the cell membrane and post-harvest senescence. This effect is supported by other findings, such as a reduction in hardness related to cell growth, protein and polysaccharide degradation and water migration (Antmann et al., 2008; Jiang et al., 2011; Oz et al., 2015). Both chewiness and hardness increased at the final stage of drying due to the removal of moisture from the mushrooms (Kotwaliwale et al., 2007).

\subsection{Sensory characteristics of MAP-treated mushrooms}

The sensory characteristics of grey OMs as determined by 30 panellists are shown in Table III. It was observed that different MAP conditions affected the sensory attributes of mushrooms in different ways. OMs packed in HNP had the worst score at the end of storage, with colour scores from 2.53 (day 5: light) to 4.37 (day 10: dark) compared with control. These findings may be due to dark zone formation and unequal colour distribution over the shelf-life as reported by Antmann et al. (2008). In addition, HNP-treated mushroom had the lowest $L^{*}$ value, indicating a loss of brightness, and HNP was thus the least effective method for retaining mushroom colour compared with control, LCP and HCP.

Although Villaescusa and Gil (2003) have reported that mushrooms changed colour over storage time, both LCP (score 2.47) and HCP (score 2.97) in the present study retained mushroom colour brightness at day 10 compared with day 5. Both methods scored 2.8 and 2.4, respectively, indicating a lighter colour than the control on day 10. Meanwhile, HNP-treated mushrooms showed no significant colour changes $(p>0.05)$ over storage time. From the results

\begin{tabular}{lcccc}
\hline & \multicolumn{2}{c}{ Colour } & Odour \\
Atmosphere packaging & Day 5 & Day 10 & Day 5 & Day 10 \\
\hline Control & $2.67 \pm 0.43^{\mathrm{bA}}$ & $2.9 \pm 0.23^{\mathrm{aA}}$ & $3.33 \pm 0.62^{\mathrm{aB}}$ & $3.53 \pm 0.61^{\mathrm{abA}}$ \\
HNP & $2.53 \pm 0.89^{\mathrm{abB}}$ & $4.37 \pm 0.49^{\mathrm{aA}}$ & $3.33 \pm 1.03^{\mathrm{aB}}$ & $4.03 \pm 0.61^{\mathrm{aA}}$ \\
LCP & $2.47 \pm 0.63^{\mathrm{bA}}$ & $2.4 \pm 0.62^{\mathrm{bA}}$ & $2.37 \pm 0.61^{\mathrm{bA}}$ & $2.57 \pm 1.22^{\mathrm{bA}}$ \\
HCP & $2.97 \pm 0.81^{\mathrm{aA}}$ & $2.8 \pm 0.99^{\mathrm{bA}}$ & $2.9 \pm 0.88^{\mathrm{aA}}$ & $2.87 \pm 0.86^{\mathrm{bA}}$
\end{tabular}

Notes: Values are mean \pm standard error (duplicate). Mean values with different lower case within each column are significantly different $(p<0.05)$. Mean values with different capital case within the same row are significantly different $(p<0.05)$. Control is normal air packaging. HNP is high nitrogen packaging. LCP is low carbon dioxide packaging. HCP is high carbon dioxide packaging

OM Pleurotus sapidus

1879
Table III. Sensory evaluation on colour and odour attributes of MAPtreated oyster mushrooms 
$\mathrm{BFJ}$

121,8

1880

obtained, the panellists considered OMs packed using LCP and HCP to be the most attractive, compared with HNP and control. HCP showed the lightest colour, with the lowest $L^{*}$ value. The outcome of HCP treatment was in agreement with a previous study of mushrooms in HCP which showed high sensory quality and acceptability for 10 days (Ares et al., 2007).

For odour evaluation, HNP gave the worst score (4.03) at day 10 and produced a strong odour compared with control (3.33). Meanwhile, HCP and LCP scored 2.9 and 2.37, respectively, at day 5 with increased values at day 10 (2.87 and 2.57), which were slightly lower than control. Significant odour changes $(p<0.05)$ were observed for HNP compared with other MAP treatments over storage time. LCP had a lower odour characteristic than HCP and HNP compared with control. Moderate to high levels of $\mathrm{CO}_{2}(10-20$ per cent) inhibits aerobic bacteria such as Pseudomonas but can stimulate lactic acid bacteria (LAB). Even though HCP-treated mushroom had a lower odour score than control, it was higher than LCP, which may originate from LAB. HNP had a stronger odour characteristic than control due to the flushed carbon dioxide in the packaging. Sandhya (2010) reported that MAP-treated mushrooms require about 5-15 per cent of $\mathrm{CO}_{2}$ inside the packaging to maintain quality. The sensory analysis results showed that HNP was the least effective method for retaining the acceptance attributes of OMs.

\subsection{Total quality index}

The TQI of MAP-treated mushrooms for nine parameters is presented in Figure 3. HCP scored the best TQI (day 5: 3.44, day 10: 4.74), followed by LCP (day 5: 4.66, day 10: 6.96), control (day 5: 4.69, day 10: 8.69) and HNP (day 5: 7.64, day 10: 13.41). Such TQI was in agreement with Djekic et al. (2017) that showed HNP as the worst TQI to end of the observed shelf-life for button mushrooms. For individual quality parameters, HNP showed significant difference $(p<0.05)$ compared to the no significant difference $(p>0.05)$ for control, HCP and LCP. At day 10, some quality parameter showed significant changes for all packaging except HCP which only showed significant changes in odour. HNP gave the strongest odour compared to control followed by HCP and the weakest LCP. Colour analysis showed

Figure 3.

Overall total quality index (TQI) of MAP treated commercial oyster mushrooms

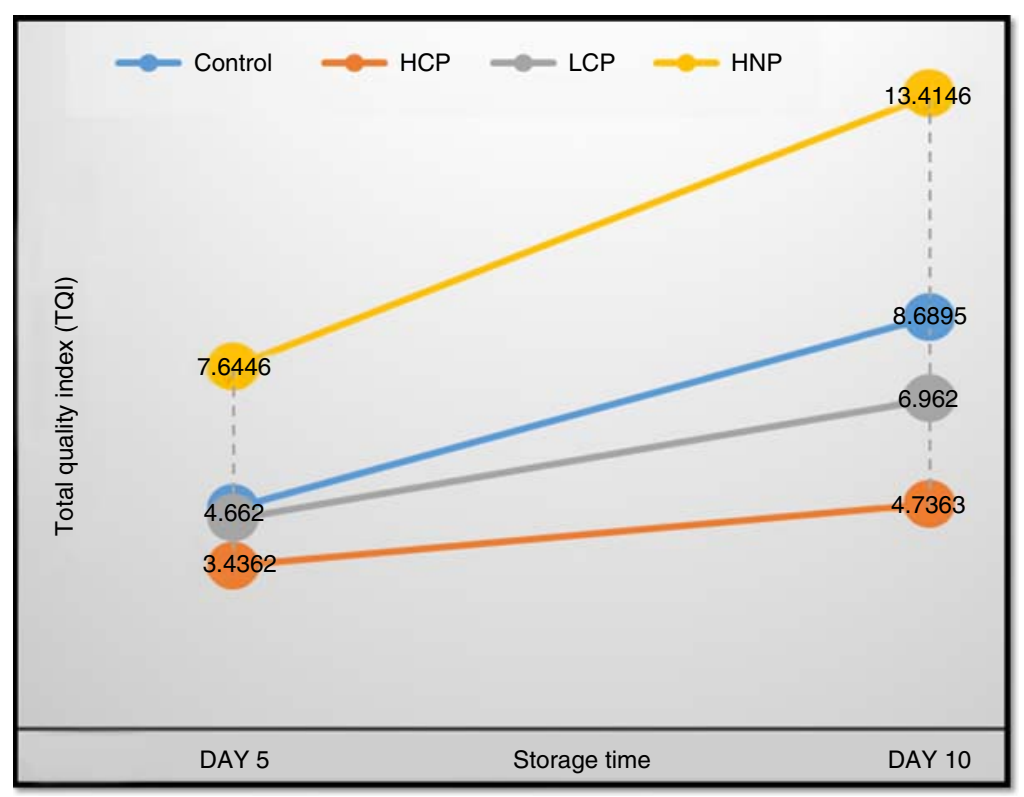


significant changes $(p>0.05)$ for all treatments for both day 5 and day 10 ; however, the panellist viewed that HNP was not significant. Meanwhile, for both textural profile and TPC, HNP gave significant variations $(p>0.05)$ over storage period compared to control. The TQI calculation method was shown to be capable of comparing and evaluating mushrooms packed in different types of atmospheric packaging (Djekic et al., 2017). As a tool for shelflife monitoring, the presented TQI model showed simplicity, reliability and precision, enabling the detection of critical quality characteristics. These physical, biological, chemical and microbiological properties or characteristics should remain within an appropriate range, limit or distribution to ensure the desired quality of products (Rathore and Kapoor, 2016). In conclusion, TQI is capable of identifying the quality index value which requires improvement (Finotti et al., 2007), and therefore represents a potential tool in post-harvest quality assurance systems. Such quality model is cost-effective and improves competitivity (Tavana et al., 2003), which may be applied in Malaysian mushroom industries.

\section{Conclusion}

The present study has investigated the TQI on harvested OM using different MAP gas mixtures and determined that the HCP retained the best quality of OM. Compared with control and LCP, HCP recorded the highest TPC and showed the highest effectiveness in maintaining the colour and odour quality of OM. Our phylogenetic analysis revealed that the commercially grown OM from Malaysia was P. sapidus strain QDR. The acceptance of sensory panellists on the fresh OM varied for different MAP treatments, and the sensory reports suggested that HCP and LCP were more effective in maintaining the qualities of OM in terms of colour and odour. We believe that our findings provide significant evidence that low-cost HCP is the most ideal and efficient packaging technique for commercial OM.

\section{References}

Ab Kadir, S., Wan-Mohtar, W.A., Mohammad, R., Abdul Halim Lim, S., Sabo Mohammed, A. and Saari, N. (2016), "Evaluation of commercial soy sauce koji strains of Aspergillus oryzae for gammaaminobutyric acid (GABA) production”, Journal of Industrial Microbiology \& Biotechnology, Vol. 43 No. 10, pp. 1387-1395.

Akbarirad, H., Kazemeini, S.M. and Shariaty, M.A. (2013), "Deterioration and some of applied preservation techniques for common mushrooms (Agaricus bisporus, followed by Lentinus edodes, Pleurotus spp.)", Journal of Microbiology, Biotechnology and Food Sciences, Vol. 2 No. 6, pp. 2398-2402.

Antmann, G., Ares, G., Lema, P. and Lareo, C. (2008), "Influence of modified atmosphere packaging on sensory quality of shiitake mushrooms", Postharvest Biology and Technology, Vol. 49 No. 1, pp. 164-170.

Ares, G., Lareo, C. and Lema, P. (2007), "Modified atmosphere packaging for postharvest storage of mushrooms: a review", Fresh Produce, Vol. 1 No. 1, pp. 32-40.

Ares, G., Parentelli, C., Gambaro, A., Lareo, C. and Lema, P. (2006), "Sensory shelf life of shiitake mushrooms stored under passive modified atmosphere", Postharvest Biology and Technology, Vol. 41 No. 2, pp. 191-197.

Argyropoulos, D., Khan, M.T. and Muller, J. (2011), "Effect of air temperature and tre-treatment on color changes and texture of dried Boletus edulis mushroom", Drying Technology, Vol. 29 No. 16, pp. 1890-1900.

Baars, J., Sonnenberg, A., Mikosch, T. and Van Griensven, L. (2000), "Development of a sporeless strain of oyster mushroom Pleurotus ostreatus", Science and Cultivation of Edible Fungi, Vol. 1 No. 22, pp. 317-323, available at: www.cabdirect.org/cabdirect/abstract/20001613056

Bi, W., He, C., Ma, Y., Shen, J., Zhang, L.H., Peng, Y. and Xiao, P. (2016), "Investigation of free amino acid, total phenolics, antioxidant activity and purine alkaloids to assess the health properties of non-Camellia tea”, Acta Pharmaceutica Sinica B, Vol. 6 No. 2, pp. 170-181. 
$\mathrm{BFJ}$ 121,8

Brennan, M., Le Port, G. and Gormley, R. (2000), "Post-harvest treatment with citric acid or hydrogen peroxide to extend the shelf life of fresh sliced mushrooms", Lebensmittel-Wissenschaft + Technologie, Vol. 33 No. 4, pp. 285-289.

Cayupan, Y.S.C., Ochoa, M.J. and Nazareno, M.A. (2011), "Health-promoting substances and antioxidant properties of Opuntia sp. fruits: changes in bioactive-compound contents during ripening process", Food Chemistry, Vol. 126 No. 2, pp. 514-519.

Djekic, I., Vunduk, J., Tomasevic, I., Kozarski, M., Petrovic, P., Niksic, M., Pudja, P. and Klaus, A. (2017), "Total quality index of Agaricus bisporus mushrooms packed in modified atmosphere", Journal of the Science of Food and Agriculture, Vol. 97 No. 9, pp. 3013-3021.

Exama, A., Arul, J., Lencki, R.W., Lee, L.Z. and Toupin, C. (1993), "Suitability of plastic films for modified atmosphere packaging of fruits and vegetables", Journal of Food Science, Vol. 58 No. 6 , pp. 1365-1370.

Finotti, E., Bersani, A.M. and Bersani, E. (2007), "Total quality indexes for extra-virgin olive oils", Journal of Food Quality, Vol. 30 No. 6, pp. 911-931.

Fonseca, S.C., Oliveira, F.A.R. and Brecht, J.K. (2002), "Modelling respiration rate of fresh fruits and vegetables for modified atmosphere packages: a review", Journal of Food Engineering, Vol. 52 No. 2, pp. 99-119.

Gao, M., Feng, L. and Jiang, T. (2014), "Browning inhibition and quality preservation of button mushroom (Agaricus bisporus) by essential oils fumigation treatment", Food and Chemical Toxicology, Vol. 149, pp. 107-113, available at: www.sciencedirect.com/science/article/pii/S0308814613015185

Hamid, M.T., Rahim, H. and Dardak, R.A. (2013), "Understanding the mushroom industry and its marketing strategies for fresh produce in Malaysia”, Economic and Technology Management Review, Vol. 8, pp. 27-37, available at: http://etmr.mardi.gov.my/Content/ETMR \% 20Vol.8\%20(2013)/3.\%20Tarmizi.pdf

Jafri, M., Jha, A., Bunkar, D.S. and Ram, R.C. (2013), "Quality retention of oyster mushrooms (Pleurotus florida) by a combination of chemical treatments and modified atmosphere packaging", Postharvest Biology and Technology, Vol. 76, pp. 112-118, available at: www.sciencedirect.com/ science/article/abs/pii/S0925521412002311

Jiang, T., Zheng, X., Li, J., Jing, G., Cai, L. and Ying, T. (2011), "Integrated application of nitric oxide and modified atmosphere packaging to improve quality retention of button mushroom (Agaricus bisporus)", Food Chemistry, Vol. 126 No. 4, pp. 1693-1699.

Klaus, A. and Nikšić, M. (2007), "Influence of the extracts isolated from Ganoderma lucidum mushroom on some microorganisms", Zbornik Matice Srpske za Prirodne Nauke, Vol. 113, pp. 219-226.

Kotwaliwale, N., Bakane, P. and Verma, A. (2007), "Changes in textural and optical properties of oyster mushroom during hot air drying", Journal of Food Engineering, Vol. 78 No. 4, pp. 1207-1211.

Liu, D., Coloe, S., Baird, R. and Pederson, J. (2000), "Rapid mini-preparation of fungal DNA for PCR", Journal of Clinical Microbiology, Vol. 38 No. 1, p. 471.

Liu, J., Wu, Y.C., Kan, J., Wang, Y. and Jin, C.H. (2013), "Changes in reactive oxygen species production and antioxidant enzyme activity of Agaricus bisporus harvested at different stages of maturity", Journal of the Science of Food and Agriculture, Vol. 93 No. 9, pp. 2201-2206.

Marangoni, A.G., Palma, T. and Stanley, D.W. (1996), "Membrane effects in postharvest physiology", Postharvest Biology and Technology, Vol. 7 No. 3, pp. 193-217.

Mohapatra, D., Bira, Z.M., Frias, J.M., Kerry, J.P. and Rodrigues, F.A. (2011), "Probabilistic shelf life assessment of white button mushrooms through sensorial properties analysis", LWT - Food Science and Technology, Vol. 44 No. 6, pp. 1443-1448.

Oz, A.T., Ulukanli, Z., Bozok, F. and Baktemur, G. (2015), "The postharvest quality, sensory and shelf life of Agaricus bisporus in active MAP”, Journal of Food Processing and Preservation, Vol. 39 No. 1, pp. 100-106.

Pardo, A., De Juan, A., Alvarez-Orti, M. and Pardo, J.E. (2010), "Screening of Agaricus bisporus (lange, imbach) strains and the casing variables for quality mushroom production in Spain", HortScience, Vol. 45 No. 2, pp. 231-235. 
Rathore, A.S. and Kapoor, G. (2016), "Implementation of quality by design for processing of food products and biotherapeutics", Food and Bioproducts Processing, Vol. 99, pp. 231-243, available at: www.sciencedirect.com/science/article/pii/S0960308516300414

Robertson, G.L. (2006), Food Packaging: Principles and Practice, CRC press, Broken Sound Parkway, NW.

Sandhya (2010), "Modified atmosphere packaging of fresh produce: current status and future needs", LWT-Food Science and Technology, Vol. 43 No. 3, pp. 381-392.

Sapata, M., Ramos, A., Ferreira, A., Andrada, L. and Candeias, M. (2009), "Quality maintenance improvement of Pleurotus ostreatus mushrooms by modified atmosphere packaging", Acta Scientiarum Polonorum Technologia Alimentaria, Vol. 8 No. 2, pp. 53-60.

Selcuk, N. and Erkan, M. (2015), "Changes in phenolic compounds and antioxidant activity of sour-sweet pomegranates cv.'Hicaznar' during long-term storage under modified atmosphere packaging", Postharvest Biology and Technology, Vol. 109, pp. 30-39, available at: www. sciencedirect.com/science/article/abs/pii/S0925521415300259

Singh, P., Langowski, H.C., Wani, A.A. and Saengerlaub, S. (2010), "Recent advances in extending the shelf life of fresh Agaricus mushrooms: a review", Journal of the Science of Food and Agriculture, Vol. 90 No. 9, pp. 1393-1402.

Tamura, K., Stecher, G., Peterson, D., Filipski, A. and Kumar, S. (2013), "MEGA6: molecular evolutionary genetics analysis version 6.0", Molecular Biology and Evolution, Vol. 30 No. 12, pp. 2725-2729.

Tavana, M., Mohebbi, B. and Kennedy, D.T. (2003), "Total quality index: a benchmarking tool for total quality management”, Benchmarking: An International Journal, Vol. 10 No. 6, pp. 507-527.

Villaescusa, R. and Gil, M. (2003), "Quality improvement of pleurotus mushrooms by modified atmosphere packaging and moisture absorbers”, Postharvest Biology and Technology, Vol. 28 No. 1, pp. 169-179.

Vukosavljević, P., Novaković, M., Bukvić, B., Niksić, M., Stanisavljević, I. and Klaus, A. (2009), "Antioxidant activities of herbs, fruit and medicinal mushroom Ganoderma lucidum extracts produced by microfiltration process", The Journal of Agricultural Science, Vol. 54 No. 1, pp. 45-62.

Wan-Mohtar, W.A.A.Q.I., Ab Kadir, S. and Saari, N. (2016), "The morphology of Ganoderma lucidum mycelium in a repeated-batch fermentation for exopolysaccharide production", Biotechnology Reports, Vol. 11, pp. 2-11, available at: www.sciencedirect.com/science/article/ pii/S2215017X16300248

Wan-Mohtar, W.A.A.Q.I., Latif, N.A., Harvey, L.M. and McNeil, B. (2016), "Production of exopolysaccharide by Ganoderma lucidum in a repeated-batch fermentation", Biocatalysis and Agricultural Biotechnology, Vol. 6, pp. 91-101, available at: www.sciencedirect.com/science/ article/pii/S1878818116300317

Wan-Mohtar, W.A.A.Q.I., Malek, R.A., Harvey, L.M. and McNeil, B. (2016), "Exopolysaccharide production by Ganoderma lucidum immobilised on polyurethane foam in a repeated-batch fermentation”, Biocatalysis and Agricultural Biotechnology, Vol. 8, pp. 24-31, available at: www.sciencedirect.com/science/article/pii/S1878818116300822

Wan-Mohtar, W.A.A.Q.I., Mahmud, N., Supramani, S., Ahmad, R., Zain, N.A.M., Hassan, N.A., Peryasamay, J. and Halim-Lim, S.A. (2018), "Fruiting-body-base flour from an oyster mushrooma waste source of antioxidative flour for developing potential functional cookies and steamedbun”, AIMS Agriculture and Food, Vol. 3 No. 4, pp. 481-492.

Zivanovic, S., Buescher, R.W. and Kim, K.S. (2000), "Textural changes in mushrooms (Agaricus bisporus) associated with tissue ultrastructure and composition", Journal of Food Science, Vol. 65 No. 8, pp. 1404-1408.

\section{Corresponding author}

Wan Abd Al Qadr Imad Wan-Mohtar can be contacted at: qadyr@um.edu.my

For instructions on how to order reprints of this article, please visit our website:

www.emeraldgrouppublishing.com/licensing/reprints.htm

Or contact us for further details: permissions@emeraldinsight.com 